\title{
Erratum
}

Adam Sowiński*, Tomasz Szczepański, and Grzegorz Koralewski

\section{Car braking effectiveness after adaptation for drivers with motor dysfunctions}

https://doi.org/10.1515/eng-2021-0072

received November 04, 2020; accepted March 09, 2021

Erratum to: Adam Sowiński, Tomasz Szczepański, and Grzegorz Koralewski. Car braking effectiveness after adaptation for drivers with motor dysfunctions. Open Eng. 2021;11:617-23. Retrieved December 1, 2020, doi: https://doi.org/10.1515/eng-2021-0060
The authors wish to change the place of employment of the co-author Grzegorz Koralewski in the article entitled "Car braking effectiveness after adaptation for drivers with motor dysfunctions," 2021;11:617-23. The right place of employment should be: Grzegorz Koralewski, Department of Logistics, Polish Air Force University, Dęblin, Poland, e-mail: g.koralewski@law.mil.pl

* Corresponding author: Adam Sowiński, Department of Diagnostics and Servicing Process, Motor Transport Institute, Warsaw, Poland, e-mail: adam.sowinski@its.waw.pl Tomasz Szczepański: Department of Diagnostics and Servicing Process, Motor Transport Institute, Warsaw, Poland Grzegorz Koralewski: Department of Logistics, Polish Air Force University, Dęblin, Poland, e-mail: g.koralewski@law.mil.pl 